\section{US haunts for Soviet spies}

\section{Washington}

THE Soviet Union has judged data obtained at Western scientific conferences to be "among the most significant" sources of information for its military development, according to a detailed assessment of West-East technology transfer published last week by the US government. The US report lists specific scientific societies and US universities that have been targeted by the Soviet Union for efforts to acquire research results with military applications.

Announcing publication of the report, Richard Perle, Assistant Secretary of Defense for International Security Policy and a known hardliner on technology transfer, said he hoped to "sensitize the scientific and technical community to the fact that there is a very large and well-organized Soviet apparatus that has targeted scientists and engineers and universities and the like for military purposes".

The report identifies two main components of the Soviet technology acquisition effort: one, managed by the Military Industrial Commission (VPK), seeks blueprints and one-off military and dual-use hardware samples for reverse engineering; the other, managed by the Ministry of Foreign Trade, seeks high-technology manufacturing and test equipment in bulk for direct use. An appendix to the report lists several hundred weapons that are claimed to have benefited directly. About 90 per cent of the documents acquired by VPK in the United States are not subject to security classification, however, and
Perle made plain his wish to see more militarily sensitive documents classified.

At least 35 scientific conferences worldwide were identified by VPK as sources of specific information during the late 1970s, according to the report. The more important include an international radar conference, a conference on integrated optics and a conference on aerospace and electronics systems held by the Institute of Electrical and Electronic Engineers. Universities selected for special attention from VPK's operatives include CarnegieMellon, Cincinnatti, Harvard, Massachusetts Institute of Technology and California Institute of Technology. Liberal publication policies of the National are blamed for having led directly to identifiable Soviet gains in aircraft design.

According to some speculations, publication of the US report, prepared by the inter-agency Technology Transfer Intelligence Committee to update a 1982 assessment, was a result of the recent spate of spies defecting or being arrested. Perle seemed to hint as much when he said that circumstances that previously precluded publication of this amount of detail no longer applied. Some critics contend, however, that the timing of publication represents an attempt to catch up in the propaganda battle with the Soviet Union leading up to the Geneva summit in November.

Tim Beardsley

"Soviet Acquisition of Militarily Significant Western Technology: An Update" is available from the US Department of Defense. Aeronautics and Space Administration

\section{Rebellion among the ranks}

\section{Washington}

THE presidents of twelve major scientific and engineering societies last week informed Secretary of Defense Caspar Weinberger that their organizations would have nothing to do with the Pentagon's new policy of imposing restrictions on access at certain unclassified conferences. The societies pledged that they "will not be responsible for, nor will they sponsor, closed or restricted access technical sessions at meetings or conferences conducted under their auspices".

The strongly worded letter is a major setback for the Pentagon's efforts to stem the flow of technical information to Eastern-bloc countries. Earlier this year the Pentagon let it be known it intended to make routine use of export control laws to restrict foreigners' access to scientific and technical data which, although not subject to national security classification, might be of mililtary significance. Such "export controlled sessions" are restricted to US nationals and to foreigners who are validated by their embassies; participants must undertake to keep the restricted in- formation confidential. Export controls are applied only to research that is not considered "fundamental".

In their letter to Weinberger, the twelve society presidents say that the new controls have the effect of placing the controlled information de facto into a new category of classification. By limiting opportunities for peer review and open discussion of research, the presidents say, the restrictions are counterproductive and detrimental to national security.

Earlier this year the Department of Defense (DoD) caused a furore at a conference of the Society of Photo-Optical Instrumentation Engineers by imposing export controls at short notice, causing the conference to be entirely re-scheduled. Later, DoD declared itself happy with the idea of export-controlled sessions for "nonfundamental" data, which it saw as a more flexible alternative to security classification. Others, apparently, were not so happy; among the signatories of last week's letter is Lewis Larmore, president of the Society of Photo-Optical Instrumentation Engineers.

Tim Beardsley
Nuclear war

\section{More gloomy forecasts}

Washington

IMMEDIATE casualties resulting from a nuclear war, the subsequent short- and long-term physiological effects, and the long-term consequences to ecosystems have probably all been underestimated by the predictions in current use. But estimates are subject to gross uncertainties that can only be reduced by more research on the "biological effects" of a nuclear war. Much should be done by the US and Soviet governments to fund such research and to inform the public of the effects. These are the main conclusions at this week's meeting of the Institute of Medicine (IoM) at the National Academy of Sciences.

According to Dr Theodore Postel of Stanford University, a hypothetical attack of 100 one-megaton bombs on 100 US urban centres would cause $36-56$ million immediate deaths, two to four times the number predicted by government studies based on blast effects alone. A onemegaton nuclear weapon can produce a fireball with a temperature of about 100 million ${ }^{\circ} \mathrm{C}$ at the centre, causing many simultaneous fires over hundreds of kilometres and hurricane-force winds. This fiery environment, together with the toxic smoke and combustion of gases, renders obsolete the "blast scaling" method of estimating the effects of a nuclear explosion used by government agencies.

One startling prediction of Postel's new "conflagration" model is that a major attack on US strategic nuclear targets would result in 16-35 million deaths and 9-41 million casualties even before the effects of fallout and damage to environmental and social systems are considered. These figures, from Dr Frank von Hippel and colleagues of Princeton University, are the outcome of the first calculations to have used computerized wind, target and population data bases apart from government studies, which are mainly classified.

The effects of toxic chemicals caused, for example, by burning of industrial plastics, is likely to have severe local consequences. Lofting of nitrogen oxides into the stratosphere would deplete the ozone layer, leading to increased ultraviolet radiation. Gases such as ammonia and methane could accumulate in the heavily polluted troposphere during periods of darkness.

Dr Frank Press, president of the National Academy of Science, summed up the general mood when he said that the "profundity of the consequences of nuclear war are such that symposia such as this ... (provide a) most valuable public service". Dr Herbert Abrams of Stanford University called for more information to be provided by the US government for 
public education and for a strengthening of screening tests to armed forces personnel because more than 5,000 personnel a year are removed from nuclear weapons handling duty because of drug abuse. alcoholism or psychological problems. The problem is likely also to be large in the Soviet Union. where alcoholism is a health problem of "epidemic proportions", he said.

The reluctance of the United States to consider the "biological" effects of nuclear war has been criticized by Dr Carl Sagan of Cornell University. Although the government in theory is providing $\$ 50$ million over 5 years to investigate the physical effects, no money is spent on biological research. One of the first studies on the ecological effects of a nuclear winter-like environment on plants is planned by Lawrence Livermore National Laboratory and the University of Wisconsin. But Dr Lynn Anspaugh of the former institute stressed the need for considerable resources to produce and continuously update an interactive model.

Maxine Clarke

Japanese exposition

\section{Tsukuba Expo strikes camp}

Tokyo

THE Tsukuba International Exposition, Japan's great high-technology extravaganza, has now closed its gates, having just squeezed past its self-declared target of 20 million visitors in its six-month run. Approximately one-sixth of the entire population of Japan - 20,334, 727 people - made the effort to go and see the wonders that science has in store for them (see Nature 314, 213-220; 1985).

In setting the 20 million goal the Expo planners, with no experience of how popular the science theme might prove, took the view that the theme probably did not matter too much: it was simply assumed that attendance would be proportional to the size of the site. The 1970 Expo held near Osaka attracted 60 million visitors, so the Tsukuba Expo, on a site just one-third of its size, should attract 20 million.

Cynics might say that it is no wonder

\section{UK atomic energy}

\section{Business not as usual}

“WE'RE not just bench R\&D; we have to be building things, getting things working". With this attitude the UK Atomic Energy Authority (UKAEA) moves into the final stages of negotiation over its reorganization into a trading fund, a change due to take effect at the start of its financial year in April 1986.

As chairman Arnold Allen announced at the presentation of the UKAEA annual report last week, trading fund status entails being run "as far as possible under the conditions of a normal commercial business" with payment for contracted work performance targets. Moreover, there will be an end to reliance on government grants to balance the books; this year UKAEA spent $£ 399.7$ million (up from $£ 380$ million) and was paid $£ 174.4$ million for its services (up from $£ 169.6$ million) with the difference provided by parliamentary vote. Remaining questions centre on "the precise financial regime" within which UKAEA will operate - the initial capital debt, borrowing ceiling and financing of basic research.

Contracts are an index of the authority's ability to get things working, according to Mr Allen. Those given to UKAEA comprise both nuclear contracts, including the supply of fuel and reactor insulation testing for the overseas market; and nonnuclear contracts, 13 per cent of UKAEA activity, which generated $£ 30$ million last year (up $£ 2$ million). Contracts worth $£ 60$ million were placed last year by the UKAEA Northern Division.

The authority's commitment to breeder reactors is evinced by its recent acquisition of a 49 per cent shareholding in Fast
Reactor Technology (Fastec), a company set up to explore the commercial exploitation of the technology. The remaining shares are owned by National Nuclear Corporation. Fastec's prospects look particularly good because fast breeder reactors seem set to be less expensive than was assumed three years ago. The capital costs alone, said Dr Tom Marsham, a UKAEA board member, could be 20 per cent less than originally forecast. After start-up costs, the reactors are predicted to become "broadly competitive" with other sources of electricity.

UKAEA's research into fast reactor technology, centred at the Dounreay facility in Caithness, is now reaching fever pitch. Both the government and the authority hope that Dounreay will receive the European reactor club's nod of approval to reprocess spent plutonium from the demonstration reactors in France and West Germany. Britain's strongest case lies in its experience with reprocessing technology, one example of which is the $£ 650,000$ "pulsed column" rig at Dounreay for solvent extraction, said to be the largest sealed glovebox in the world.

Planning permission would have to come first and the Scottish Secretary, Mr George Younger, echoed the need for haste by limiting the inquiry, planned for early next year, to local issues. According to Dr David Locke of the Northern Division, an environmental assessment will be presented at the inquiry; but environmentalists see the move as preempting any concern besides that of the UKAEA to stay on top. Elizabeth Collins that attendance turned out to be proportional to the size of the site - it was simply a matter of the physical limits of how many people can be packed into one space. But there may be a better explanation for why the 20 million goal was reached so neatly. Expo organizers knew they might otherwise come out in the red and in the past few weeks public enthusiasm has been whipped up with feverish campaigns. In a tremendous closing rally, one-third of a million people turned up on Sunday, breaking all previous records and pushing attendance to the 20 million mark.

For the Expo organizers, the attendance figures mean that they may end up with around Y1,000 million (US $\$ 4$ million) in profits, which is not so bad. Things have not been so profitable, however, for the hundreds of small shops set up in the Expo grounds to sell souvenirs and food. Many have lost money heavily. Angry shopholders blame poor siting and bad organization, some are refusing to pay their rent and others are taking legal action.

The Expo's biggest hit was Fujitsu's three-dimensional computer-generated film which included an astonishing sequence of a DNA molecule being wound and rewound and packed into a chromosome. The theatre was completely full for almost every showing throughout the whole run. Biggest attendance figures of all were claimed by the Matsushita pavilion with more than five million visitors coming to see the portrait-drawing robot, which numbered Prime Minister Nakasone among its sitters.

Many foreign visitors were disappointed that there was so little substance to the Expo and so much spectacle; its aim sometimes seemed to be merely to accustom the Japanese people to a hightech future whose coming had already been decided for them. But not only foreigners were critical: a group with considerable distrust of the intentions of the commercial electronics makers whose pavilions dominated the Expo launched their own alternative "AXPO 85" on a site nearby.

The Expo site is now to be cleared of its accumulated pyramids, cones, spheres and other fantastic structures in order to be turned into an industrial park. But some bits of the Expo will live on. The Chinese government is rumoured to be interested in buying some of the high-tech exhibits for a fair that will give the Chinese people a vision of what they are striving for. The Volvo articulated double shuttle buses are to go to Australia. And the Fuyo theatre's robots are likely to be bound for Disneyland in Florida. There, no doubt, they will feel much happier than they ever were at a science Expo.

Alun Anderson 